\section{Cureus}

\title{
Premodern Transcendental Perspectives on the Missing Heritability Problem and Some Intelligence Conundrums
}

Ted Christopher 1

1. Rochester Center for Biomedical Ultrasound, University of Rochester

$\square$ Corresponding author: Ted Christopher, tchrist7@rochester.rr.com

Disclosures can be found in Additional Information at the end of the article

\section{Abstract}

The common premodern transcendental understanding of life is explored here as a basis for alternative explanations to some biological mysteries, in particular, a collection of intelligence-related phenomena, and more generally, the missing heritability problem ("transcendental" will be used herein in place of a number of existing terms including "transmigration" and "reincarnation"). An extended introduction considers possible carryover from previous lives as a complementary component of life and, specifically, as an additional vehicle for apparent heredity. This introduction also touches on two relevant examples - the innate spiritual or religious understandings of young children and the mysteries associated with monozygotic twins. The subsequent discussion section then considers a constellation of three intelligence-related mysteries - a childhood behavioral syndrome, the Einstein Syndrome; the somewhat overlapping phenomena of savants and prodigies; and then the observed rise in IQ's or the Flynn Effect - which together with the inability to identify a significant DNA basis for the variations in intelligence, represent a significant challenge to the modern understanding of humans. Alternative explanations from the transcendental perspective are considered along the way.

Categories: Miscellaneous

Keywords: savants, prodigies, missing heritability, reincarnation, einstein syndrome, flynn effect, religion and science

\section{Introduction}

A basic pillar of the modern scientific understanding of life, as Richard Dawkins has put it, is that our DNA "created us, body and mind" [1], and as such, we are very fortunate "to be alive, given that the vast majority of people who could potentially be thrown up by the combinatorial lottery of DNA will in fact never be born" [2]. This view of DNA as individual-defining and along with it of conception as a lottery-like event, are in turn pillars of the ultimate scientific theory of life - evolution. Thus, the title of Francis S. Collins' recent book about DNA, The Language of Life, and the enormous efforts to identify and understand the DNA bases for the variations in complex disease susceptibilities and eventually for other individual-distinguishing features [3].

This vision has turned out to be difficult to confirm, though. In September 2008, Duke University's geneticist David B. Goldstein was quoted on the outcome of thorough comparisons between the million or so common genetic (or DNA) variations and the apparent inheritance patterns associated with the occurrences of common complex diseases [4]. It had naturally been assumed that some of these common variations in DNA blueprints would be correlated with the patterns of susceptibility to common diseases (and, of course, to other inborn 
differences amongst individuals). But Goldstein pointed out that:

After doing comprehensive studies for common diseases, we can explain only a few percent of the genetic component of most of these traits. For schizophrenia and bipolar disorder, we get almost nothing; for Type 2 diabetes, 20 variants, but they explain only two to three percent of familial clustering, and so on.

Goldstein then added:

It's an astounding thing that we have cracked open the human genome and can look at the entire complement of common genetic variants, and what do we find? Almost nothing. That is absolutely beyond belief.

This missing heritability problem is, of course, of great theoretical and practical interest.

This very surprising situation has apparently grown as the subsequent DNA search efforts have yet to uncover much of the expected DNA origins [5-7]. Confident news may continue - such as with the junk DNA headlines of September 2012 - but significant findings still appear to be missing (the junk DNA news rush was later characterized by one researcher as essentially an "orchestrated PR campaign" [8]). A split amongst researchers over the possible character of the missing DNA origins - either "hidden as numerous rare variants of large effect or as common variants of very small effect" [6] - was reported in 2010 [5] and appears to have continued to at least 2012 [6]. In a 2012 blog contribution, researcher Dr. Kevin A. Mitchell acknowledged that a "debate is raging in human genetics" over this missing heritability problem [9].

An alternative take on this situation can be found by considering the common premodern transcendental understanding of life in which there is a complementary soul or spirit contribution and that this non-material aspect can have far-reaching effects. On the prevalence, as given in M'Clintock and Strong's Cyclopaedia of Biblical, Theological and Ecclesiastical Literature, "[t]ransmigration, dating back to a remote antiquity, and being spread all over the world, seems to be anthropologically innate, and to be the first form in which the idea of immortality occurred to man" [10]. This belief has two aspects, the intuitive behavioral/personality continuity part and the much more puzzling cause-and-effect (or popularly "karma") part. Of these two logically distinct hypotheses, it has been claimed that they were historically "in fact ... virtually always conjoined" [10]. Perhaps the apparent continuity of personalities across lives in small and undistracted populations initiated and then amplified the credibility of the continuity hypothesis. Perhaps the karma hypothesis then followed on occasion from observing an individual encountering their apparent just deserts across lives.

A transcendental understanding would be consistent with our innate dualism and also with individual cases suggestive of young children experiencing an explicit recall of a previous life [11-12] (a more detailed case can be found in [13]). The behavioral continuity aspect appears to offer traction on a number of other puzzling behaviors, including those involving prodigies, transgender individuals, and the surprising personalities found amongst a number of species [14-15]. It also provides a simple explanation for the behavioral differences found between monozygotic twins and more generally suggests a consistent framework for the behavioral side of the missing heritability problem [16]. With the second - the cause-and-effect -

transcendental component, there could be consistency with the unexpected health differences found between monozygotic twins and, moreover, with the disease susceptibility/occurrence 
portion of the missing heritability problem. In brief, the missing origins for a number of our individual specifics could be understood as carryover from previous lives and with some exceptional behaviors - as with prodigies and prodigious savants - there could be some additional carryover consistent with some of the remarkable descriptions of the disembodied state.

A further suggested generalization is that significant transcendental import would likely be overlapping with, and also complementary to, the DNA's import. If, as some traditions assert, the incarnating soul is drawn to their parents-to-be, then that soul might tend to find some continuity in the conception-beget DNA specifics - beyond the species- and sex-default codes. This could include DNA-determined unusual conditions. But beyond this overlapping aspect, though, the odds that the crapshoot of conception would deliver a variable DNA match for a soul's overall trajectory is zero. The DNA definition would have to be breached in many ways. Thus, to the degree that science can show that the conception-beget DNA, plus realistic environmental impacts define individuals, then this would minimize the import associated with possible transcendental phenomena. In this regard, efforts to confirm the DNA expectations of behavioral genetics and also to account for the surprising differences found between monozygotic twins are of considerable interest. Now, three examples will be considered to enliven this introduction.

The book by Justin L. Barrett, Born Believers - The Science of Children's Religious Belief [17], laid out some of the growing evidence that infants tend to possess an innate belief in the existence of souls/God/gods, to be believers in what Barrett termed a "natural religion." The book contained some striking examples, including ones in which the positions of atheists' were rebutted by their young children. As Barrett wrote "[c]hildren are prone to believe in supernatural beings, such as spirits, ghosts, angels, devils, and gods, during the first four years of life ..." [17]. He later wrote [17]:

\section{Exactly why believing in souls or spirits that survive death is so natural for children} (and adults) is an area of active research and debate. A consensus has emerged that children are born believers in some kind of afterlife, but not why this is.

These striking findings were placed within the scientific vision, though. Even as a practicing Christian, Barrett simply concluded that these are evolution-beget illusional tendencies. The one glimpse of an alternative interpretation was provided at the beginning of the book in which Barrett gave the explanation offered confidently by a man he encountered on an Indian train. That man had explained [17]:

[T]hat on death, we go to be with God and are later reincarnated. As children had been with God more recently, they could understand God better than adults can. They had not yet forgotten or grown confused and distracted by the world.

This traditional transcendental explanation is what is being considered herein and the particulars of a possible overlapping and complementary relationship between the incarnating soul or spirit aspect and the evolved material-only aspect will be introduced. The stated complexity of the disembodied realm - involving perhaps "spirits, ghosts, angels, devils, and gods" - will not be considered, although a premodern description of post-death intellectual capacities will be considered for their possible import to some intellectual conundrums.

The second example considered here is monozygotic or identical twins, and it highlights some 
of the challenges facing the modern understanding of life. The cause of their origin - the initial split or division of a single cell zygote - is a mystery. So is the fact that it only occurs in some species. Further, similar appearances, aside the empirical realities of the such twins, constitute a significant rebut to the DNA "created us body and mind" logic. For example, when one monozygotic twin is gay, then the other twin is gay in only about $20-30 \%$ of cases (against a backdrop overall gay frequency of two to four percent) [3].

In general, monozygotic twins, whether they were raised together or separately, have been observed to on average be more different than alike personality-wise [18-19]. Studies suggest that such twins can closely share the same environment or inhabit separate ones and still they appear to have comparably different personalities. In a succinct statement of these surprising differences, one conjoined (attached) monozygotic twin commented that "[w]e are two completely separate individuals who are stuck to each other. We have different world views, we have different lifestyles, we think very differently about issues" [18].

Yet, even in the case in which identical twins were separated at birth, they can still share remarkably specific behavioral tendencies -- from the small and questionable behaviors (some shared small preferences might be found between any pair of individuals) to the big and lifedefining ones - like becoming very dedicated volunteer firemen [20]. Such phenomena have been used as strong evidence for the life-defining import of DNA, but set against the large and seemingly innate personality differences, it may be just another mystery.

The surprising health differences between monozygotic twin pairs was covered in a $2006 \mathrm{New}$ York Times article [21]. That article opened by describing a healthy and active 92-year-old and her identical twin. The latter "is incontinent, she has had a hip replacement, and she has a degenerative disorder that destroyed most of her vision ... [and] has dementia." Yet, the sisters have the same DNA, grew up together, and lived in the same place. They also had quite different personalities and ambitions.

The centerpiece of that article was a description of a large study comparing the variations in longevities found amongst identical and same-sex fraternal (or dizygotic) twins. Since the former share all of their variable DNA and the latter only half, comparisons like this are used to estimate the relative import of DNA. The study's twin populations totaled 10,251 pairs. Amongst them, the identical twins died only a little closer than the fraternal twins, and specifically, the deaths of the identical twins averaged "more than 10 years apart." The related scientific paper gave the inferred genetic component as covering - "about a quarter of the variance in adult lifespan" - and pointed out somewhat surprisingly that, "the genetic influences on lifespan are minimal before the age of 60 and only increase after that age" [22].

The final monozygotic puzzle considered here is the remarkable bond that tends to exist between them. Sometimes when identical twins are separated at birth and then reunited "as adults, they say they feel like they have known each other all their lives" [19]. In one of my childhood neighborhoods, I can't even remember the local twins being apart. Given that siblicide is common in nature [23], does this really make sibling-sense?

A potential transcendental explanation for monozygotic twins is as follows: Identical twins were close before their current life, perhaps having recently been siblings, close friends, coworkers, or spouses. Such scenarios are consistent with some reports from modern investigations into possible cases of reincarnation [11]. This previous closeness brought them together to be born as monozygotic twins and was the underlying cause of the initial split of the single cell zygote. Continuity of behavioral tendencies tends to result in their roughly similar personalities - as is often found between those who are close - and also provides for some shared preferences. Their previous connection, including perhaps their shared disembodied 
experiences, provides a basis for their unbelievable closeness. Superficially, such twins are material-only replicas produced by the same DNA blueprint, but underneath there are two separate beings with mostly separate backgrounds, accounting for much of their otherwise remarkable differences.

A suggestive final example was found in Darold A. Treffert's fascinating book, Islands of Genius [24]. The description of a modern prodigy there was as follows [24]:

By age five, Jay had composed five symphonies. His fifth symphony, which was 190 pages and 1,328 bars in length, was professionally recorded by the London Symphony Orchestra for Sony Records. On a 60 Minutes program in 2006 Jay's parents stated that Jay spontaneously began to draw little cellos on paper at age two. Neither parent was particularly musically-inclined, and there were never any musical instruments, including a cello, in the home. At age three, Jay asked if he could have a cello of his own. The parents took him to him to a music store, and to their astonishment, Jay picked up a miniature cello and began to play it. He had never seen a real cello before that day. After that, he began to draw miniature cellos and placed them on music lines. That was the beginning of his composing.

Jay says that the music just streams into his head at lightning speed, sometimes several symphonies running simultaneously. "My unconscious directs my conscious mind at a mile a minute," he told the correspondent on that program.

This was an example of what led Treffert to conclude that prodigal behavior typically involves "know[ing] things [that were] never learned." Additionally, whatever their origins some prodigal capacities seem to challenge biological feasibility. This last example introduces the remainder of this paper and its consideration of some remarkable intellectual phenomena.

\section{Materials And Methods}

Relevant observations of some intellectual mysteries were reviewed and some potential explanations from the premodern transcendental perspective were considered.

Introductory literature considered for an assessment of biological mysteries included some recent articles in the New York Times and Scientific American. General life science books by authors, including Francis Collins, Richard Dawkins, Judith Harris, Ernst Mayr, and Steven Pinker, were considered. Books considered that were close to the transcendental hypotheses included those authored by Justin L. Barrett, Joseph Head and S. L. Cranston, Thomas Sowell, Ian Stevenson, and Jim Tucker.

Finally, the books used for consideration of specific transcendental intellectual import were limited to: The Tibetan Book of the Dead - the Great Liberation Through Hearing in the Bardo by Francesca Fremantle and Chogyam Trungpa [25], Peaceful Death, Joyful Rebirth - A Tibetan Buddhist Guidebook by Tulku Thondup [26], and I AM THAT by Nisargadatta [27]. There must be - or at least have been - many more relevant premodern teachings or perspectives, but these are ones that I am familiar with. Interested readers can see some of Ian Stevenson's writings for a few specifics on some existing cultures with a transcendental view [11] or dig out an old academic book like Reincarnation in World Thought by Joseph Head and S. L. Cranston [10] for a broad historical take. 


\section{Results}

Discussion

\section{Intellectual mysteries - The Einstein Syndrome}

Thomas Sowell's book The Einstein Syndrome - Bright Children Who Talk Late considered a very interesting behavioral phenomena named for the late physicist, Albert Einstein [28]. (Sowell is the well-known economist and author.) Sowell pointed out that children with this condition have "speech development [which] lags far behind that of other children their age, while their intellectual development surges ahead of their peers" [28]. These children often are very strong-willed, late in toilet training, and their intellectual strengths are focused in analytical areas and/or music. They also tend to demonstrate exceptional memories. In adult terms, these kids appear to be born quite strongly nerd-inclined ("nerd" is not a slight). Another prominent characteristic is that they are almost always born into families with a strong technical and/or musical presence.

The Einstein Syndrome considered children fitting this description whose parents had come together in two groups. One group represented the experiences of 43 biological families and was connected with Thomas Sowell, while the other group represented 232 biological families under the auspices of Professor Camarata, a speech pathologist at the Vanderbilt University Medical Center [28]. With the inclusion of a few families with multiple late-talkers, the respective counts of biological children were 45 and 236. The median age of beginning to speak in the smaller group connected to Sowell was four years old, while the figure for the children in Professor Camarata's group was three and a half [28]. In the smaller group, most kids "did not make a statement using more than one word until they were at least three and a half years old and their first complete sentence was spoken when they were four" [28].

For comparison, normal development of a child's speech progresses from single word utterances and then at "around 18 months, the child starts to combine single words into two word sentences" [29]. Subsequently, their "[v]ocabulary typically grows from around 20 words at 18 months to around 200 words at 21 months" [29]. Furthermore, the large Stanford-based Terman study (1925-59) of gifted children (with IQ's of 140-ish and up) found they tended to talk earlier than their lower IQ peers [29].

Sowell had previously written a book, Late-Talking Children, [30] on this subject and had a son who had exhibited this syndrome. Professor Camarata had also had a son with this syndrome and he himself had had it as well. Almost $90 \%$ of the children in these groups were boys [28]. Also notable was that 26 percent of the children in Sowell's group had a close relative who had exhibited this syndrome, whilst the corresponding figure for Camarata's group was 48 percent $[28]$.

A "striking" characteristic of the Einstein Syndrome was that the associated families "are highly atypical - and highly analytical" in their occupations [28]. Of the late-talking children considered, almost three-quarters "had at least one close relative who was either an engineer, a scientist, or a mathematician" [28]. Close relatives in this context were limited to parents, grandparents, aunts, uncles, and additionally for Camarata's group, siblings. The children in the study groups were about 10 times as likely to have fathers who were engineers as were latetalking children in general that had been considered in a British study [28]. It is noteworthy that this association with a family type perhaps mirrors a weaker correlation observed between the occurrence of autism and technical families considered by Simon Baron-Cohen in a November 2012 Scientific American article.

Also observed was also a big musical connection. In both groups, about three-fourths of the 
kids had a close relative who played a musical instrument. In Camarata's group, $28 \%$ of them had a close relative who was a professional musician, and in Sowell's group, that figure was $26 \%$ [28]. This appeared to be another relatively focused activity correlated with the occurrence of this syndrome within a family.

Some of the stories involving these children exhibiting the Einstein Syndrome were amazing. In one instance, the three year old "silent" son of a professor was involved in the following [28]:

The older boy, now five, had learned to read and would entertain his doting parents by doing so aloud. One evening he came upon a word he did not recognize, and struggled with it. At which point his brother toddled over, peered at the text and read out the sentence perfectly. Following that, he again lapsed into silence for several months and only then began to speak easily.

In another case, a toddler "became deeply absorbed in listening to Bach, to the point of being moved to tears" [28]. Sowell also wrote that "one of the five-year-old preschoolers in my group helped both his mother at home and his teacher at school when they had problems using the computer (circa the 1990s). He could also play the piano with his eyes closed"

[28]. Extraordinary child lock breaking abilities were exhibited by Sowell's son prior to the age of one [28].

In a brief detour from Sowell's coverage, a prodigy appearing to fit the Einstein Syndrome profile and described in an article on raising prodigies is considered [31]. Here is an excerpt:

Drew Petersen didn't speak until he was $31 / 2$, but his mother, Sue, never believed he was slow. When he was 18 months old, in 1994, she was reading to him and skipped a word, whereupon Drew reached over and pointed to the missing word on the page.

Drew went on to apparently learn to read quite a bit of sheet music on his own, skip the first six months of formal piano lessons at age five, and then within the year was "performing Beethoven sonatas at the recital hall at Carnegie Hall." On the way to kindergarten, at one point Drew asked his mom, "[c]an I just stay home so I can learn something?" His mom recently commented, "[h]e was reading textbooks this big, and they're in class holding up a blowup M."

Thomas Sowell also considered some earlier experiences of adults who apparently had had the syndrome (including Albert Einstein). One was the pianist, Arthur Rubenstein, who demonstrated a remarkable draw to the piano as a young child [28]:

[he] became fixated on the piano. Whenever he was asked to leave the drawing room where [it] was kept, he screamed and wept. He began playing the piano at age three. When his father later brought him a violin to play, little Arthur reacted by smashing it, earning himself a spanking.

Sowell commented that such strong-willed behavior "will be all too familiar" to Einstein Syndrome parents. Further Rubenstein [28]:

[a]fter hearing a performance of the first suite of Edvard Grieg's Peer Gynt, [he] returned 
home 'to play almost all of it - to the amazement of the family.' At this point,

Rubenstein was not yet five years old and had not yet begun formal instruction under a

professional musician. At age seven, he gave his first public performance.

Another remarkable developmental syndrome, the Williams Syndrome (roughly the opposite of the Einstein Syndrome), was also touched on.

These amazing behaviors led Sowell to title an explanatory chapter on it, "Groping for Answers." There he carefully laid out some hypotheses about possible brain developmental dynamics which could underlie the specific patterns of the observed aptitudes. Beneath this, he favored a DNA/heredity basis, indirectly supported by the analytical-orientations of the families and also by some earlier occurrences of the syndrome amongst close relatives.

With instances of the Einstein Syndrome, most other siblings were normally developing, though [28]. Additionally, of course, most high aptitude technical and/or musical people didn't follow this pattern. Given the rarity of the syndrome, a DNA explanation would seem likely to involve some form of a mutation, but is it realistic for a mutation to produce such behaviors? Is it plausible for a biomolecular code to specify for an obsession with the piano? Also, how could the relevant mutations be so localized to this type of family?

A possible explanation from the transcendental perspective is as follows: A being who became highly focused in a previous technical and/or musically-occupied life was reborn and brought along some of their behavioral tendencies and relative capabilities. This behavioral skew was also carried over and reflected in their brain as well, and this combination could have resulted in the delayed speech. Also, a symptom associated with a person being very intellectually focused is that they also tend to be out of touch with their body, and this could have been reflected in the phenomenon of delayed toilet training. The fact that such children were predominantly found in technical and/or musically-connected families reflected the tendency of an incarnating-being to be drawn to similar and/or previously related parents. From this perspective, one might expect that this syndrome would not be found within cultures that do not support analogous careers. Have there been any Albert Einstein's born in groups that don't support scientific investigative careers (or more particularly, distant from such groups)?

The above transcendental take on the Einstein Syndrome portrays some basic elements of a possible transcendental dynamic. The incarnating soul tends to be drawn to local, similar, and/or previously related parents. This dynamic would be consistent with the crude heredity patterns that underlie modern DNA expectations, for example, in the field of behavioral genetics. Further, although The Einstein Syndrome did not report on measured brain characteristics, it is likely that the children exhibiting these unusual innate characteristics also had correlated brain features. Likewise, there have been reports of images of brains in which features of high intelligence stood out; yet, the observed correlation between intelligence scores and variations in DNA is only about one percent [32-33]. This could be viewed as an example of a transcendental Lamarckian-like effect (of note, the Lamarckian concept has been scientifically resuscitated in connection with possible epigenetic inheritance effects). Perhaps similarly bright children are much more likely to experience myopia [28] and amongst autistic or retarded musical prodigies "a majority ... have been either congenitally blind or severely visually impaired" [28]. (Sowell used these points in part as supportive of a heredity-based explanation for the Einstein Syndrome.)

\section{Intellectual mysteries - savants}

The second challenge considered here involves the behavior of savants as depicted in Darold A. Treffert's book, Islands of Genius [24]. In addition to traditional autistic savants, this book also 
considered the recently recognized acquired savant syndrome in which savant behavior appears in the wake of a central nervous system setback. The book also considered sudden savant syndrome in which savant skills seem to appear out of the blue. Treffert's Preface provided the following introductions to some of the savant terrain [24]:

Kim Peek, the inspiration for the movie Rain Man, memorized 12,000 books. He is the Mt. Everest of memory with bottomless factual recall in multiple areas of expertise including history, geography, literature, music, sports, science, and religion, to name only some. He became a living Google. But as a child, his parents were advised to put him in an institution. One doctor suggested a lobotomy.

Matt Savage, who couldn't stand noise or being touched as a child, very quickly mastered the piano at age $61 / 2$ and had his first CD of jazz composition at age eight. Matt is recognized worldwide now as "the Mozart of Jazz," a title conferred on him by the famous jazz artist, Dave Brubeck. At age 17, he is the leader of the Matt Savage Trio, giving concerts around the globe. He recently recorded his eighth CD.

Leslie Lemke is blind, severely cognitively impaired and has cerebral palsy. Yet, he played Tchaikovsky's Piano Concerto No. 1 flawlessly after hearing it for the first time at age 14. Leslie, who has never had a music lesson in his life, is a musical genius.

After a 15-minute helicopter ride over London, Stephen Wiltshire, in a five-day drawing marathon, produced a spectacularly accurate four meter long sketch which captures with mind-boggling fidelity seven square miles of London - building by building, street by street, window by window. Diagnosed with autism at age three, he was described as a "rocket of young talent" on the scene at age eight. Stephen was invested by Queen Elizabeth II as a Member of the Order of the British Empire and now has his own gallery in the Royal Opera Arcade in London.

These extraordinary people, and others like them ... have savant syndrome, a rare but remarkable condition in which incredible abilities - "islands of genius" - coexist side by side, in jarring juxtaposition, to certain disabilities within the same person.

Also, in the preface, Treffert suggested that [24]:

no model of brain function, including memory, will be complete until it can fully incorporate and explain this jarring contradiction of extraordinary ability and sometimes permeating disability in the same person. Until we can fully explain the savant, we cannot fully explain ourselves nor comprehend our full capacities.

For Treffert, there appeared to be little doubt that these remarkable behaviors arose solely from the physical processes of the brain. The central mystery for him was the origins of those savantfunctioning brains. His explanation involved what he called "genetic memory," and in particular, that savants have somehow tapped into our shared DNA-based storage of knowledge 
and skills and then implemented them in the hardware of their brain. He thus offered a technical analogy of factory-installed software on a computer. His specific storage vehicle was the epigenome, the conditioned side-kick of the genome (via molecules effecting the enfoldment of the chromatin).

In about half of the cases, this syndrome occurred concurrently with an autistic disorder, and in the rest, the underlying disorder was a brain injury or disease. Of particular interest were the prodigious savants whom Treffert believed would have been characterized as geniuses or prodigies if they didn't also have the coexisting disability. In that regard, there is some overlap here with the previously considered Einstein Syndrome.

Some distinguishing characteristics of prodigious savants include the ability to demonstrate extraordinary memory and also exceptional but narrowly focused skills. Such savants are believed to be very rare with "probably fewer than 100 known prodigious savants living worldwide" [24]. Treffert described five areas that the savant skills appear to be focused in calendar calculating (usually finding the day of the week associated with a specified date), music, art, mathematical and number skills (including super-fast calculations), and mechanical or spatial skills [24].

Treffert detailed some of the brain changes that have been found to be associated with savant syndrome [24]. These typically involve some damage to the left hemisphere and then subsequent compensatory changes and efforts on the part of the brain's right hemisphere. Here is a somewhat concise description [24]:

disruption of typical left hemisphere function from prenatal influences - such as detrimental hormonal effects on the cortex from circulating testosterone - or other injurious prenatal, perinatal or postnatal development in children and adolescents, or from later brain injury or disease in adults. These injuries produce compensatory right brain skills and abilities to offset left brain dominance. In addition, there is simultaneously, probably from those same detrimental factors, injury to the corticolimbic (cognitive or semantic memory) circuits with substitution and reliance on (habit or procedural) memory circuits. This combination of left brain and cortico-limbic circuitry damage, with compensatory right brain skills and reliance on habit and procedural memory, produces the clinical picture that is savant syndrome.

That there are corresponding changes in the brain is perhaps only part of the functional story. Was the memory exhibited by Stephen Wiltshire after a 15 minute helicopter ride or Kim Peek's book recall really feasible within the current understanding of the brain and neurons?

Another striking memory feat presented by Treffert came from Oliver Sacks' book, An Anthropologist on Mars. It involved a man named Franco Magnani who experienced a serious but unknown illness which had effects including "delirium" and "perhaps seizures" [24]. After recovering, "Magnani began painting immaculately accurate scenes from the village of Pontito [Italy] where he had grown up, but had left at age 18." In addition to the "digital-fidelity recall," the painting skills and interest appeared to come out of the blue. Magnani was quoted, "Fantastic. How could I do it? And how could I have had the gift and not known about it before?" Other examples of "massive autobiographical memory" or hyperthymesic syndrome were also given. Again, does such memory seem brain-only feasible? What about the associated energy demands? 
Central to Treffert's effort was trying to account for the inexplicable savant learning. The examples given in the book appeared to strongly support his contention that "they indeed know things [and exhibit skills] that they never learned" [24]. An article citing Treffert stated that he "maintains a registry of about 300 'savants' who, through a head injury or dementia, acquire skills they never learned" [34]. He believes that the epigenome (in particular, as optimistically portrayed in the NOVATV episode, "Ghost in Your Genes") is the vehicle for such transmission and claimed simply "[b]ottom line: genetic memory exists" [24]. There do not appear to be reports suggesting anything like this capability is plausible, though, and in fact researcher, Eric Nestler, acknowledged in an interview with Scientific American that any epigenetic inheritance effect is "controversial" [35].

Before considering a possible transcendental take on some of the savant phenomena, some comments on the principal source here, The Tibetan Book of the Dead (TBD), are in order [25]. This book was apparently written in the 8th century by a religious teacher named Padmasambhava, and it contains instructions to aid a dying or recently deceased person in dealing with the presumed subsequent intermediate (or bardo) state. This text was thus often read at the bedsides of the dying or recently deceased. The intermediate state was believed to be very tumultuous, but it also offered great potential to, at minimum, secure a good rebirth. The coauthor and late Tibetan teacher, Chogyam Trungpa, offered a modern synopsis in his commentary [25]:

There is something which continues, there is the continuity of your positive relationship with your friends and the teaching, so work on that basic continuity, which has nothing to do with the ego. When you die, you will have all sorts of traumatic experiences, of leaving the body, as well as your old memories coming back to you as hallucinations. Whatever the visions and hallucinations may be, just relate to what is happening rather than trying to run away. Keep there, just relate with that.

Trungpa's commentary also emphasized an interpretation of underlying energies in the bardos. Another teacher, Tulku Thondup, characterized the bardo experience as "like a dream journey, fabricated by our own habitual mental impressions" [26]. Much of the TBD contains very explicit suggestions, apparently for those of Tibetan Buddhist-flavored "habitual mental impressions." The soul's intentionality is viewed as a key, and thus one of the repeated instructions is to maintain an attitude dedicated to the betterment of "all sentient beings."

It is the associated description of the post-death or bardo soul that is of particular interest here. It is stated several times that "in the bardo state, the mind becomes nine times more clear" and is also that the associated memory is such that even if the TBD was "heard ... only once and the meaning not understood", then after death "it will be remembered with not even a single word forgotten" [25]. This claimed clarity and memory capability, though, would presumably compete within the bardo against the claimed "visions and hallucinations."

A crude transcendental explanation of the savant syndrome could then begin with simple transcendental continuity, and thus, the inexplicable learning and interests were carried over from past lives. More particularly, if a person was very interested and strongly habituated to an activity, then that tendency might continue in the intermediate state and ultimately beget a rebirth with extraordinarily focused behavioral tendencies. In a physics-sense, they caught a resonance and this carried over strongly into their subsequent life. Perhaps such a process could allow some of the underlying "nine times more clear" soul-mind to shine through in a focused way and thus some of the spectacular and modern-inexplicable prodigious savant feats. Analogously, the acquired savant syndrome could reflect neural setbacks that 
inadvertently opened a window for the functioning of the underlying soul-mind. On this note, the similarity between some pre-epileptic seizure experiences (involving an "intense heightening of awareness" and not "abnormal or fantastic visions") and some transcendental mystical awakening experiences [36] could then be literal and not neural-only phenomena and/or based on hallucinations [37].

Finally, an additional very specific bardo description and possible savant connection comes from Tulku Thondup's book, Peaceful Death, Joyful Rebirth. In it, he wrote that [26]:

[s]ome people relive their dying experiences, exactly as they went through them, on every seventh day after their death, again and again, especially if it was a tragic death. That is why every seventh day is observed by survivors with prayers and dedications.

Facing such a scenario would likely whittle down your perspective on things and strongly frame time in a cycle-of-seven (or modulo seven) days perspective. With savant syndrome, the most common - "almost universally, present" - unusual ability and focus is with calendar calculating. Why and how this happens is an enormous mystery. Central to it appears to be a fixation on time through a day of the week (or modulo seven) perspective.

\section{Intellectual mysteries - The Flynn Effect}

The third and final mystery considered here is the Flynn Effect. Philosopher James Flynn (and some lesser-noted earlier researchers) noticed that IQ scores in many countries appeared to be rising during the twentieth century [38-39]. Although there is no shortage of controversy here, the apparent rising IQ's are not in question. The "bombshell", as Steven Pinker put it, "is that the Flynn Effect is almost certainly environmental" [38]. How such an environmental dynamic could have evaded previous studies - and everyday perception - of intelligence is truly amazing.

The apparent intelligence gains are not subtle as Steven Pinker pointed out [38]:

[a]n average teenager today, if he or she could time-travel back to 1950, would have an IQ of 118. If the teenager went back to 1910, he or she would have had an IQ of 130, besting 98 percent of his or her contemporaries. Yes, you [read] that right: if we take the Flynn Effect at face value, a typical person today is smarter than 98 percent of the people in the good old days of 1910. To state it in an even more jarring way, a typical person of 1910, if time-transported forward to the present, would have a mean IQ of 70, which is at the border of mental retardation. With the Raven's Progressive Matrices, a test that is sometimes considered the purest measure of general intelligence, the rise is even steeper. An ordinary person of 1910 would have an IQ of 50 today, which is smack in the middle of mentally retarded territory, between "moderate" and "mild" retardation.

The underlying gains have been largely in the abstract reasoning portions of intelligence tests, such as those containing similarities, analogies, and visual patterns (including Raven's Matrices). Little, if any, gains occurred in the traditional main topics of education - knowledge, math, and vocabulary [38, 39]. Thus, arguments connecting these gains to improvements in schooling appear to be inadequate. 
Flynn feels that these increases in IQ scores reflect a pervasive shift in modern societies towards more focus on abstract reasoning [38-40]. In particular, Flynn hypothesized that this shift involved "scientific reasoning" infiltrating "everyday thinking" on an increasingly wide scale $[38,40]$. Steven Pinker offered an explanatory description that many modern people have apparently "assimilated hundreds of these [scientific] abstractions from casual reading, conversation, and exposure to the media, including proportional, percentage, correlation, causation, control group, placebo, representative sample, false positive, empirical, ..." [38]. With such a hypothesized environmental shift, Flynn suggested that "we developed new cognitive skills and the kind of brain that can deal with them" [40].

The mystery associated with the Flynn Effect is how this could have happened, given the relatively fixed nature of an individual's intelligence quotient. As intelligence researcher, Linda Gottfredson, put it, "decades of genetics [inference-based] research have shown, ... [that] genetic endowments are responsible for much of the variation in mental ability among individuals" [41]. Additionally, Gottfredson pointed out that:

\section{[A]lthough shared environments do have a modest influence on IQ in childhood, their effects dissipate by adolescence. The IQs of adopted children, for example, lose all resemblance to those of their adoptive family members and become more like those of the biological parents they have never known.}

Certainly some adoptions - particularly, international ones - would seem to have environmentally realized something akin to the time travel hypothesized by Pinker. So why isn't the Flynn Effect also apparent via the environmental dynamics experienced by some individuals?

Additionally, the limited real-world import of these apparent gains in aptitude was vividly suggested by Linda Gottfredson's in citing the complexity barriers encountered in a 1993 literacy survey of American adults [42]. Included was the observation that only 17 percent were able to use "a bus schedule to determine the appropriate bus for a given set of conditions" and only three percent were able to "answer the most complex questions, like determining the total cost of carpet to cover a room (using a calculator)."

Nonetheless, the puzzling gains in our aptitude for abstract reasoning beg an explanation. From a transcendental perspective, this could be explained as a Lamarckian-like effect due to the increased emphasis on abstract reasoning in the modern world. From this perspective, there has been a transcendental boost in innate abstract reasoning abilities as souls have cycled through (human) lives with more and more emphasis on abstraction. This would be similar to the earlier explanations for the gains found with the Einstein Syndrome and savants, but without the big focal boost. This would also be consistent with the innate intelligence differences between individuals (and groups), differences which so far have been minimally connected to DNA. Thus, the differences in the intellectual demands, possibilities, and pursuits across transcendental trajectories could have beget different cumulative Lamarckian-like contributions to the innate intelligences of individuals.

Such a transcendental process would place the environmental influence for contemporary intelligence score gains in the previous lives of individuals, with the most recent life perhaps being the dominant contributor. The alternative of trying to account for contemporary gains amidst modern society's increasingly distracted norms (and reduced physical activity) is difficult. Flynn in fact commented, "[t]o my amazement, in the 21st century the increases are continuing" and went on to add, "as if guided by an invisible hand" [39]. 


\section{Conclusions}

A number of challenges remain in confirming science's material-only vision of life. Prominent amongst these are identifying the DNA origins of our apparent individual

inheritances. Identifying the origins of the variations in our innate intelligences is a significant example. A recent report had an explanation proposing a default high level of intelligence with the variations being imposed in a downward fashion via random mutations [33]. But as the examples considered here reveal, instances of high intelligence can pose their own conundrums. Also, how our evolutionary history could have beget such high levels is difficult to imagine.

The premodern transcendental vision of life whereby there is a complementary spirit or soul aspect was introduced herein is one alternative. Perhaps best considered as an explanation for some unexpected behaviors (as with the transgender phenomenon), it could also offer some general import as with the missing heritability problem and literally for our innate sense of dualism. To the degree that it were independent of heredity, then such a complementary process would have been independent of the evolution of the material aspect of life.

The transcendental vision was very common amongst premodern people, and thus, there were probably many hypothesized theories of possible mechanics. In the modern world, a few people have investigated this traditional vision, including researchers of possible individual cases of reincarnation [11-12] (see Stevenson's work for a fuller list), and even not so long ago, philosophers and other intellectuals contemplated the implications as detailed in the works of Head and Cranston [10]. This premodern vision could offer some insight into modern puzzles, and perhaps with some objective credibility, it could also offer some motivational help, beginning with our sustainability crisis.

The work here has focused on human beings, but arguments could be made for other species, too. Some of the anomalous behaviors observed amongst other species could be consistent with transcendental contributions [14-15]. If a soul changed species in its incarnations, then perhaps personality would be a tangible thread. Consistent with the missing heritability problem, simpler animals, such as flies and roundworms, have shown surprising variations under genetically identical and tightly controlled laboratory circumstances [19]. Analogously in the TBD, there is a passage warning of the possibility of incarnates ending up in "an ant-hill or a worm-hole" [25].

Also contained in the Tibetan Book of the Dead are many descriptions of the tendencies of souls to be overwhelmed by their own visions in the bardo. If there were something to the suggested intelligence-dynamic, then there could be a parallel connection to be found in the realm of mental illnesses.

Finally, some descriptions of the nature of the soul can be found in the sources considered here. In the TBD, there is duality in such descriptions between a passive (or "emptiness") aspect and an active (or "luminosity") aspect. Here is an excerpt [25]:

[t]hese two, your mind whose nature is emptiness without any substance whatever, and your mind which is vibrant and luminous, are inseparable: this is the dharmakaya of the Buddha. This mind of yours is inseparable luminosity and emptiness in the form of a great mass of light, it has no birth or death ...

Somewhat of a complement to the TBD can be found in the far-ranging and earnest discussions of the book I AM THAT, based on talks with the late Indian teacher, Nisargadatta. The challenge 
discussed therein was maintaining close observations of the living experience so as to appreciate phenomena as-is, without getting caught up in identification, memories, and "excess imagination." Here is a simple and subjectively-oriented excerpt in which Nisargadatta answers a question on identity [27]:

[t]here is no difference between us; nor can I say that I know myself, I know that I am not describable nor definable. There is a vastness beyond the farthest reaches of the mind [i.e., workings of the brain]. That vastness is my home; that vastness is myself. And that vastness is also love.

\section{Additional Information \\ Disclosures}

Human subjects: All authors have confirmed that this study did not involve human participants or tissue. Animal subjects: All authors have confirmed that this study did not involve animal subjects or tissue. Conflicts of interest: In compliance with the ICMJE uniform disclosure form, all authors declare the following: Payment/services info: All authors have declared that no financial support was received from any organization for the submitted work. Financial relationships: All authors have declared that they have no financial relationships at present or within the previous three years with any organizations that might have an interest in the submitted work. Other relationships: All authors have declared that there are no other relationships or activities that could appear to have influenced the submitted work.

\section{References}

1. Dawkins R: The Selfish Gene.. Oxford University Press, New York, NY; 1976.

2. Dawkins R: The God Delusion. . Houghton Mifflin Company, New York, NY; 2006.

3. Collins F: The Language of Life: DNA and the Revolution in Personalized Medicine. . Harper Collins, New York, NY; 2010.

4. Wade N: A Dissenting Voice as the Genome is Sifted to Fight Disease . New York Times,. September 16, 2008,

5. Hall SS: Revolution Postponed. Sci Am. 2010, 303(4):60-7. http://www.scientificamerican.com/article.cfm?id=revolution-postponed

6. Gibson G: Rare and common variants: Twenty arguments. Nature Review Genetics . 2012, 13:135-145.

7. Luhrmann TM: Beyond the Brain. The Wilson Quarterly. 2012, Summer:28-34.

8. Junk DNA, Junky PR. (2012). Accessed: June 13, 2013: http://blogs.scientificamerican.com/guest-blog/2012/09/17/junk-dna-junky-pr/.

9. I’ve got your missing heritability right here.... (2012). Accessed: June 13, 2013: www.wiringthebrain.com/2012/02/ive-got-your-missing-heritability-right.html .

10. Head J, Cranston SL: Reincarnation in World Thought. Julian Press, New York, NY; 1967.

11. Stevenson I: Where Reincarnation and Biology Intersect. Praeger Publishers, Westport, CT; 1997.

12. Tucker J: Life Before Life - A Scientific Investigation of Children's Memories of Previous Lives. St. Martin's Press, New York, NY; 2005.

13. Leininger B, Leininger A, Gross K: Soul Survivor - The Reincarnation of a World War II Fighter Pilot.. Grand Central Publishing, New York, NY; 2009.

14. Siebert G: The Animal Self. New York Times Magazine,. January 22, 2006,

15. Angier N: Even Among Animals: Leaders, Followers and Schmoozers. New York Times,. April 5, 2010,

16. Christopher T: The Almost Obvious Case for a Transcendental Understanding of Life . Explore (NY). 2011, 7(6):363-368.

17. Barrett JL: Born Believers - The Science of Children's Religious Belief. . Free Press, New York, NY; 2012. 
18. Harris JR: No Two Alike.. W. W. Norton \& Company, New York, NY; 2006.

19. Pinker S: Blank Slate: The Modern Denial of Human Nature. . Viking, New York, NY; 2002.

20. Segal NL: Indivisible by Two - Lives of Extraordinary Twins. . Harvard University Press, Cambridge, MA; 2005.

21. Kolata G: Live Long? Die Young? Answer Isn’t Just in Genes . New York Times,. August 31, 2006,

22. Christensen K, Johnson TE, Vaupel JW: The quest for genetic determinants of human longevity: Challenges and insights. Nature Review Genetics . 2006, 7:436-447.

23. Tenneson M: Siblicide - Who Says You Have To Be Nice To Your Brother? . Wildlife Conservation. September/October 2006,

24. Treffert DA: Islands of Genius - The Bountiful Mind of the Autistic, Acquired, and Sudden Savant.. Jessica Kingsley, London, UK; 2012.

25. Fremantle F, Trungpa C: The Tibetan Book of the Dead. . Shambhala Publications, Boston, MA; 1992.

26. Thondup T: Peaceful Death, Joyful Rebirth. . Shambhala Publications, Boston, MA; 2005.

27. Nisargadatta S: I AM THAT.. Acorn Press, Durham, NC; 1973.

28. Sowell T: Einstein Syndrome - Bright Children Who Talk Late. . Basic Books, New York, NY; 2001.

29. Smith PK, Cowie H, Blades M: Understanding Children’s Development, Third Edition.. Blackwell Publishers, Malden, MA; 1998.

30. Sowell T: Late Talking Children.. Basic Books, New York, NY; 1998.

31. Solomon A: How Do You Raise a Prodigy . New York Times Magazine,. October 31, 2012,

32. Zimmer C: The Search for Intelligence. Sci Am. 2008, 299(4):68-75.

33. Dobbs D: If Smart is the Norm, Stupidity Gets More Interesting . New York Times,. October 22, 2012,

34. Carvajal D: On the Trail of Inherited Memories . New York Times,. August 17, 2012,

35. The Mind's Hidden Switches. (2011). Accessed: June 13, 2013: www.scientificamerican.com/podcast/episode.cfm?id=the-minds-hidden-switches-11-11-22.

36. Sekida K: Zen Training.. Weatherhill, New York, NY; 1985.

37. Sacks O: Seeing God in the Third Millennium . The Atlantic,. December 2012,

38. Pinker S: The Better Angels of Our Nature - Why Violence has Declined. . Viking Books, New York, NY; 2011.

39. Folger T: Can We Keep Getting Smarter. Sci Am. 2012, 307(3):44-7.

40. Flynn JR: Thinking in More Sophisticated Ways. New York Times,. February 27, 2012,

41. Gottfredson LS: The General Intelligence Factor. Scientific American Presents - Intelligence. Winter Quarter 1999,

42. Gottfredson LS: The World Grows More Complex. New York Times,. February 27, 2012, 